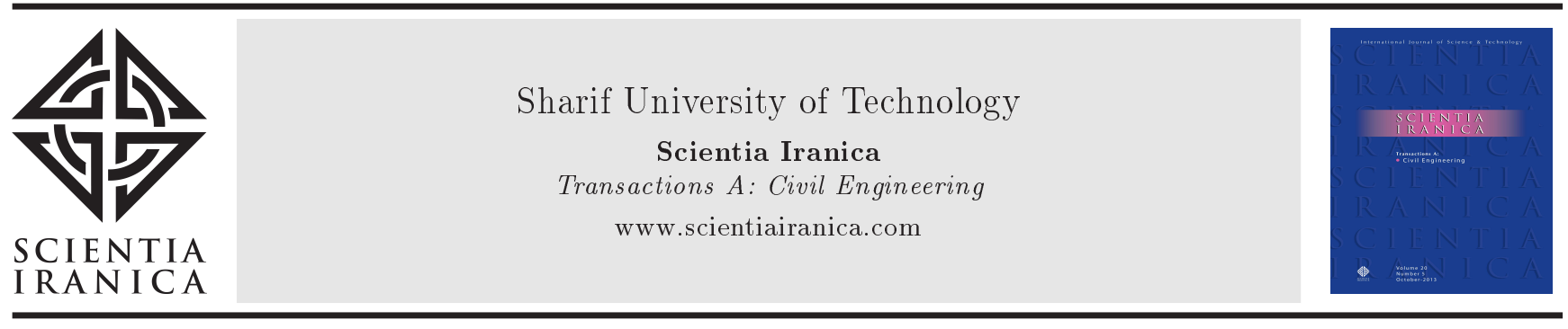

\title{
Strength and elastic moduli of a concrete bridge using advanced nondestructive techniques
}

\author{
M.A. Hadianfard ${ }^{\mathrm{a}, *}$, H. Marzouk ${ }^{\mathrm{b}}$ and C. Shafieyan ${ }^{\mathrm{b}}$ \\ a. Department of Civil and Environmental Engineering, Shiraz University of Technology, Shiraz, P.O. Box 71555313, Iran. \\ b. Department of Civil Engineering, Faculty of Engineering and Architecture, Ryerson University, Toronto, ON, Canada, M5B $2 K 3$.
}

Received 29 July 2015; received in revised form 20 January 2016; accepted 13 February 2016

\author{
KEYWORDS \\ Ultrasonic pulse \\ velocity; \\ Shear wave velocity; \\ Compressive strength; \\ Dynamic modulus of \\ elasticity; \\ Nondestructive test; \\ Mira-3D.
}

\begin{abstract}
In this research, Non-Destructive Test (NDT) wave tomography techniques are used to estimate the strength and elastic moduli and to assess the health condition of the piers of an existing concrete bridge. There are various empirical relationships to evaluate concrete characteristics based on NDT techniques. However, it is not clear which empirical relationship matches the desired concrete better. Therefore, using only one empirical model can lead to inaccurate results. In the current investigation, the mean value of several appropriate relationships is considered as the desired value. Also, the use of only one NDT technique causes some errors. In order to accurately estimate the concrete characteristics, the combination of two or more nondestructive methods is very efficient. In this research, data of Ultrasonic Pulse Velocity (UPV) and shear wave velocity tests are used simultaneously. The results show that the combination of the two criteria of strength and elasticity and using an average value of several empirical models give a relatively accurate scale for assessment of the concrete condition. The results show the ability and efficiency of the combination of two different NDT methods to estimate the strength, elastic moduli, and health condition of the concrete structure.
\end{abstract}

(C) 2017 Sharif University of Technology. All rights reserved.

\section{Introduction}

Non-Destructive Tests (NDT), such as the Ultrasonic Pulse Velocity (UPV) test and shear wave tomography (MIRA-3D), are very good choices to evaluate the quality and strength of concrete and also to detect the presence, size, and location of damages in existing buildings. These tests are fast, efficient, and easy to perform and are of low cost. Therefore, these techniques are considered by many engineers and researchers to assess the condition and vulnerability of structures [1-5]. Various NDT techniques, such as UPV tomography and impact-echo, have been used by many

*. Corresponding author. Tel.: +98 7137277656

Email addresses: hadianfard@sutech.ac.ir (M.A.

Hadianfard); hmarzouk@ryerson.ca (H. Marzouk);

cshafiey@ryerson.ca (C. Shafieyan) researchers to assess concrete bridges [6-8].

The research by Carcano and Moreno [9] was focused on studying pulses passing through concrete specimens to propose a model for assessing the quality of concrete made with limestone aggregates. Through artificial neural networks and using ultrasonic pulse velocity, Kewalramani and Gupta [10] and also Bilgehan and Turgut [11] predicted concrete compressive strength. Trtnik et al. [4] used MATLAB software to provide a model for prediction of concrete compressive strength based on neural networks and ultrasonic pulse velocity. Dawood et al. [7] used NDT methods for assessment of the condition of an existing bridge structure. Their investigation included concrete microscopic crack inspection, impact-echo test, and shear wave testing (MIRA) to detect different defects inside the concrete girders and pre-stressed ducts. To assess concrete structures by ultrasonic test 
equipment, such as MIRA and Eyecon, Haza et al. presented several case studies, including laboratory and field applications, on various types of structures and materials [12]. Malcolm and Honggang used different test techniques in several case studies for examination of the advantages and limitations of each test [13]. Some researchers, such as Bishko et al. [14] and Birgul [15], studied concrete characteristics by obtaining the shear wave velocity in the concrete. Furthermore, many researchers investigated mechanical and elastic properties of various types of fresh and hardened concretes [16-18]. Other researchers, such as Salman and Al-Amawee [19] and Popovics [20], worked particularly on the calculation of static and dynamic moduli of elasticity of concrete and the relationship between these moduli. A review of major research studies in the field of earthquake engineering of bridges is presented by Less and Adeli [21]. Their study included computational modeling, nonlinear simulation, hazard analysis, bridge damage studies, health monitoring of bridges, and retrofitting of bridges. Vasseghi et al. [22] presented the results of an experimental study on existing multicolumn concrete bridge bent constructed in Iran to identify the vulnerabilities of the bridge and to develop an appropriate retrofit method to alleviate such vulnerabilities.

The scope of this investigation employs combined NDT techniques to provide an accurate assessment regarding the structural condition of piers of a concrete bridge. The data of ultrasonic, plus those of velocity and shear wave velocity tests, are used simultaneously to calculate the strength and elasticity properties of the existing concrete. To increase the accuracy of the research work, the average value of most appropriate empirical relationships is considered as the desired value.

The main focus of this research is on a concrete bridge located in Ontario, Canada, which was constructed about 50 years ago. The bridge is comprised of steel girders with a composite concrete deck and concrete piers and abutments. The concrete piers are rectangular with dimension of $1.2 \mathrm{~m} \times 1.2 \mathrm{~m}$. The piers are reinforced by bars with diameter $25 \mathrm{~mm}$, at spacing $65 \mathrm{~mm}$ and concrete cover $40 \mathrm{~mm}$. In this study, 18 concrete piers of the bridge are assessed using NDT methods. In the recent years, some cracks and damages have been seen at the bridge piers; therefore, some rapid repairs and rehabilitation works have been carried out on the bridge piers, including removal of loose and deteriorated concrete, concrete restoration, and patch repair. However, the main problem has not been solved completely, and more studies are required to assess the damage further.

\section{Measurement of the pressure wave velocity}

The Pressure Wave (Primary or P-Wave) is a type of

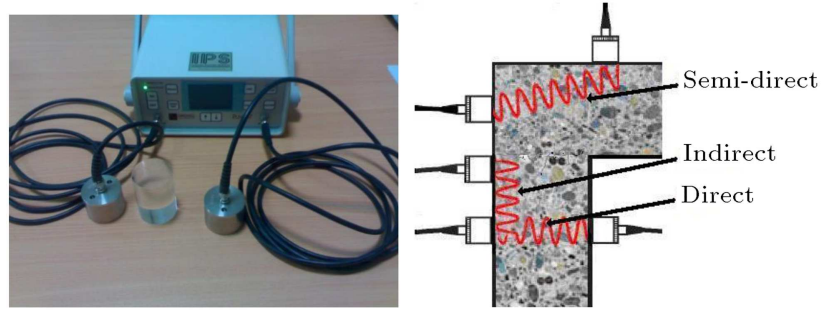

Figure 1. Ultrasonic pulse velocity device.

ultrasonic wave which travels longitudinally, and thus makes particles vibrate in the direction of the travel. These waves are commonly used in NDT equipment such as Ultrasonic Pulse Velocity (UPV) and ImpactEcho. In this study, the UPV instrument is used to determine the $\mathrm{P}$-wave velocity on the concrete. Figure 1 illustrates a UPV device. The apparatus includes a processor unit that sends and receives ultrasonic pulses and measures the time between the two operations (sending and receiving). It also has two probes connected to two cables, which perform the transmission of ultrasonic pulses. The test procedure consists of measuring the time of travel of an ultrasonic pulse passing through the concrete sample. In a comparative manner, a higher velocity is obtained when concrete is of better quality in terms of density, uniformity, compressive strength, etc.

As shown in Figure 1, there are three types of arrangements for probes in a UPV test: direct transmission, semi-direct transmission, and indirect or surface transmission. It is evident that the most desirable arrangement is the direct transmission type, since among the three possibilities, the pulse which is transmitted and received with this arrangement is of the highest energy. In this study, only direct transmission is considered. The UPV test has been performed on 18 piers of the bridge, each tested at various points and at different sides. The mean value of total measurements on each pier is considered as velocity of the P-wave.

\section{Measurement of the shear wave velocity}

The shear wave (S-wave or transverse wave) vibrates particles perpendicular to the direction of travel and provides a clearer image from inside of the tested specimen. MIRA-3D shear wave tomography is a modern NDT apparatus for measuring the shear wave velocity and for scanning the concrete members. This testing apparatus is shown in Figure 2. The obtained data are processed using a technique known as synthetic aperture focusing (SAFT), which transforms the data along the scanned lines into a $3 \mathrm{D}$ representation of the tested member. The MIRA-3D can be applied to detect various defects in the concrete. In images by MIRA, anomalies are shown as different colors based on their 


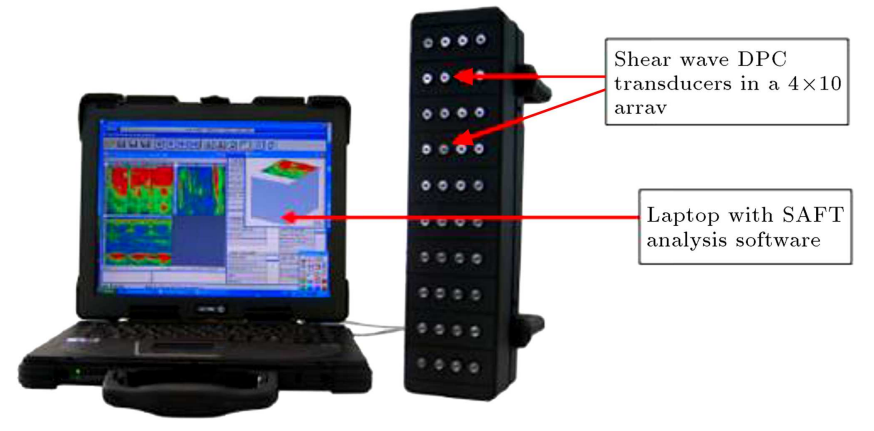

Figure 2. MIRA 3D shear wave tomography apparatus.

density characteristics. The obtained image provides information about thickness of the member, voids, cracks, reinforcement, and their corrosion locations, poor-quality bond members, etc. [23].

The shear wave speed is predetermined by MIRA during the initial calibration for the test object. The MIRA shear wave velocity is calibrated based on the concrete characteristics of the testing member. The calibration process employs firing waves using forty sensors at various locations on the member to obtain an average calibrated velocity. The calibration process guarantees high quality scans and provides a more accurate representation of the member. In addition to the velocity assessment, the wave frequency significantly changes the obtained results. The wave frequency is used as an adjustment on the amount of the data collected. Where a clearer image is required, the use of high frequencies is appropriate. However, lower frequencies are used for high sensitivity to any anomalies within the specimen [23].

The test operation includes the measurement of S-wave velocity and scanning the concrete surface to generate a $3 \mathrm{D}$ image about the internal condition of the concrete. This image can be used to assess cracks, voids, and internal damages. In this paper, only the results of S-wave velocity are used and the results of 3D images are not considered. However, the 3D images indicated the presence of several small voids in some piers, and no major deterioration was noted.

\section{Calculation of compressive strength of the concrete piers using $P$-wave velocity}

There is no exact or determined relationship between P-wave velocity and concrete compressive strength. However, empirical relationships can be introduced by simultaneously measuring the $\mathrm{P}$-wave velocity and the compressive strength of concrete. To estimate the compressive strength of concrete according to the pulse velocity, several relationships have been suggested, one of which is an exponential function as Eq. (1):

$$
F_{C}=A e^{B V_{p}}
$$

where $F_{C}$ is concrete strength, $V_{P}$ is P-wave velocity, and $A$ and $B$ are curve fitting constants. Since this relation is empirical, constants $A$ and $B$ should be obtained empirically by curve fitting techniques $[4,5]$. As an example, the least squares method can be used to fit the proper diagram and to determine the constants. The best curve is the one from which the sum of squared distances of the experimental points is minimal. The correlation coefficient $(R)$ can be used to determine the accuracy of the obtained relationships and their compatibility with the test results. $R$ being close to 0 means that there is little relation between the variables; when it is close to 1 , there is a strong relation between the variables. A correlation greater than 0.8 is generally described as strong, whereas a correlation less than 0.5 is generally described as weak. The $R$-squared $\left(R^{2}\right)$ method or coefficient of determination may be used instead of correlation coefficient $(R)$ to represent the percentage of variables explained by a proposed model (fitted curve). For instance, a value of $30 \%$ indicates that $30 \%$ of the variables will be explained by the fitted curve, or $70 \%$ are unexplained.

Turgut (2004) determined the $A$ and $B$ constants for prediction of compressive strength of existing concrete structures. In this study, the data are obtained from numerous cores taken from different reinforced concrete structures at different ages and unknown mix designs. The proposed formula is shown in Eq. (2). This formula enables one to predict concrete strength in existing buildings whose concrete mix design is not available [3]:

$$
F_{C}=1.146 e^{0.77 V_{P}} .
$$

In this relationship, concrete strength $\left(F_{C}\right)$ is in $\mathrm{MPa}$, and $\mathrm{P}$-wave velocity $\left(V_{P}\right)$ is in $\mathrm{km} / \mathrm{Sec}$. The coefficient of determination for this equation is $R^{2}=0.80$, which indicates that the accuracy of the relation is relatively good.

Carcano and Moreno [9] obtained a comparable relation for concrete made from crushed limestone aggregates. This relationship is shown in Eq. (3). The correlation coefficient for this model was obtained equal to 0.78 that is in the acceptable range:

$$
F_{C}=0.5697 e^{V_{P}}
$$

where concrete strength $\left(F_{C}\right)$ is in $\mathrm{MPa}$, and $\mathrm{P}$-wave velocity $\left(V_{P}\right)$ is in $\mathrm{km} / \mathrm{Sec}$. In addition to the curve fitting technique and using an exponential function, the Artificial Neural Network (ANN) approach can be used to estimate compressive strengths of concrete using UPV data. Bilgehan and Turgut [11] utilized an ANN approach for evaluation of the relationship between concrete compressive strength and UPV data. The approach used the experimental data obtained from many cores taken from different reinforced concrete 
structures with different ages and unknown ratios of concrete mixtures. The presented approach enables one to practically find concrete strengths in the existing reinforced concrete structures. The proposed relationship is shown in Eq. (4):

$$
F_{C}=0.8822 e^{0.0008 V_{P}}
$$

where concrete strength $\left(F_{C}\right)$ is in $\mathrm{MPa}$, and $\mathrm{P}$-wave velocity $\left(V_{P}\right)$ is in $\mathrm{m} / \mathrm{sec}$.

Different types of aggregates may be used in making a concrete. Also, the ratios of concrete mixtures are usually highly variable. Then, the existing empirical relationships give different results for prediction of concrete strength. Hence, it is not clear which formulation is more compatible with the old concrete of the bridge piers. Therefore, using only one empirical model to estimate the strength of concrete can lead to unrealistic results, and using the average value of several appropriate empirical models is thus more accurate. Hence, the mean value of several relationships can be considered as an accepted value of the concrete strength. Table 1 shows the calculated values for concrete strength of bridge piers based on the above relationships. The last column of this table gives the average of the different relationships and is considered as the final result.

\section{Calculation of elastic modulus of the concrete piers}

The modulus of elasticity is an important property in analysis and design of structures. For example, $E$ is needed for calculating the stiffness matrix in structural analysis in order to calculate the deflection of beams and slabs, and for determining the deformation and sway of tall buildings. The modulus of elasticity ( $E$ value) is a material property that describes stiffness. $E$-value is in fact the ratio between stress and strain. As concrete is not an elastic material, the relationship between stress and strain is not linear; therefore, the $E$-value is not constant for all ranges of stress. Three different methods for calculation of the $E$-value are shown in Figure 3. According to this figure, the three conventional $E$-values are the secant modulus, the tangent modulus, and the initial tangent modulus $[5]$.

The elastic modulus can be measured using either static or dynamic tests. The two procedures do not yield an equal value. The static modulus $\left(E_{C}\right)$ is defined as the ratio of the axial compressive stress to axial strain for a concrete cylinder under uni-axial loading. The static modulus is usually obtained from the secant modulus (chord modulus). However, the dynamic modulus $\left(E_{d}\right)$ is the ratio of stress to strain

Table 1. Computation of the compressive strength of concrete piers.

\begin{tabular}{cccccc}
\hline $\begin{array}{c}\text { Piers } \\
\text { no. }\end{array}$ & $\boldsymbol{V}_{\boldsymbol{P}}(\mathbf{m} / \mathbf{s})$ & $\begin{array}{c}\boldsymbol{F}_{\boldsymbol{C}}(\mathbf{M P a}) \\
\mathbf{E q .}(\mathbf{2})\end{array}$ & $\begin{array}{c}\boldsymbol{F}_{\boldsymbol{C}}(\mathbf{M P a}) \\
\mathbf{E q .}(\mathbf{3})\end{array}$ & $\begin{array}{c}\boldsymbol{F}_{\boldsymbol{C}}(\mathbf{M P a}) \\
\mathbf{E q} \cdot(\mathbf{4})\end{array}$ & $\begin{array}{c}\boldsymbol{F}_{\boldsymbol{C}}(\mathbf{M P a}) \\
\text { Mean value }\end{array}$ \\
\hline $\mathbf{1}$ & 4,163 & 28.27 & 36.61 & 24.66 & 29.85 \\
$\mathbf{2}$ & 4,354 & 32.75 & 44.32 & 28.73 & 35.26 \\
$\mathbf{3}$ & 4,070 & 26.32 & 33.36 & 22.89 & 27.52 \\
$\mathbf{4}$ & 4,276 & 30.84 & 40.99 & 26.99 & 32.94 \\
$\mathbf{5}$ & 4,140 & 27.77 & 35.78 & 24.21 & 29.25 \\
$\mathbf{6}$ & 4,221 & 29.56 & 38.80 & 25.83 & 31.40 \\
$\mathbf{7}$ & 4,075 & 26.42 & 33.53 & 22.98 & 27.64 \\
$\mathbf{8}$ & 4,247 & 30.16 & 39.82 & 26.37 & 32.12 \\
$\mathbf{9}$ & 4,231 & 29.79 & 39.19 & 26.04 & 31.67 \\
$\mathbf{1 0}$ & 4,083 & 26.58 & 33.80 & 23.13 & 27.84 \\
$\mathbf{1 1}$ & 4,240 & 30.00 & 39.54 & 26.22 & 31.92 \\
$\mathbf{1 2}$ & 4,316 & 31.80 & 42.66 & 27.87 & 34.11 \\
$\mathbf{1 3}$ & 4,199 & 29.06 & 37.95 & 25.38 & 30.80 \\
$\mathbf{1 4}$ & 4,206 & 29.22 & 38.22 & 25.52 & 30.99 \\
$\mathbf{1 5}$ & 4,155 & 28.10 & 36.32 & 24.50 & 29.64 \\
$\mathbf{1 6}$ & 4,116 & 27.26 & 34.93 & 23.75 & 28.65 \\
$\mathbf{1 7}$ & 4,175 & 28.53 & 37.05 & 24.89 & 30.16 \\
$\mathbf{1 8}$ & 4,085 & 26.62 & 33.86 & 23.17 & 27.88 \\
\hline & & & & &
\end{tabular}




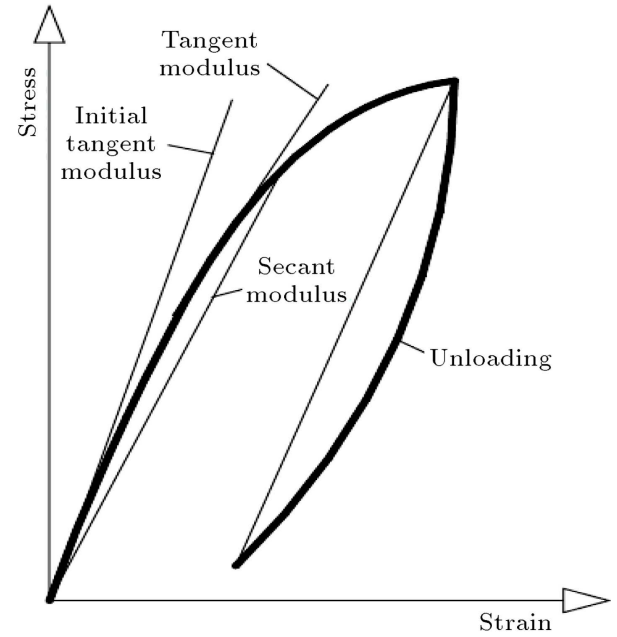

Figure 3. Calculation of concrete elastic modulus from the stress-strain curve.

under vibratory conditions (calculated from data obtained from either free or forced vibration tests). Since, compared to static testing, a considerable amount of applied stress is absent in the dynamic test, no micro cracking is caused in the concrete, and there is no creep. Therefore, the dynamic modulus corresponds to nearly elastic states. For this reason, the dynamic modulus is considered to be approximately equal to the initial tangent modulus determined in the static test. As a result, the dynamic modulus (initial tangent modulus) is appreciably higher than the static modulus (secant modulus), and the ratio of the static modulus to the dynamic is always smaller than unity [5].

\subsection{Calculation of the dynamic elastic modulus}

The in-situ structural properties, such as modulus of elasticity, cannot be measured directly without damaging the structure itself. $E$ is usually evaluated from the compressive strength $\left(f_{c}^{\prime}\right)$ of the concrete using empirical relations rather than being directly measured. Also, non-destructive methods can be used for measuring $\mathrm{P}$ - and $\mathrm{S}$-wave velocities to estimate the in-place dynamic modulus.

The basic theory of ultrasonic wave propagation in concrete was explained by Jones $[1,24]$. Relationships between parameters of elasticity of a solid, such as concrete, are formulated as follows:

$$
\begin{aligned}
& V_{P}=\sqrt{\frac{E_{d}(1-\vartheta)}{\rho(1+\vartheta)(1-2 \vartheta)}}, \\
& V_{S}=\sqrt{\frac{E_{d}}{2 \rho(1+\vartheta)}}, \\
& V_{R}=\frac{0.87+1.12 \vartheta}{1+\vartheta} \sqrt{\frac{E_{d}}{2 \rho(1+\vartheta)}},
\end{aligned}
$$

where $V_{P}, V_{S}$, and $V_{R}$ represent the velocities of pressure, shear, and surface waves, respectively ( $\mathrm{P}-$, $\mathrm{S}$-, and R-waves), $\rho$ is density of the solid, and $\vartheta$ is Poisson's ratio.

Combining Eqs. (5) and (6) gives the Poisson's ratio as in Eq. (8):

$$
\vartheta=\frac{V_{P}^{2} / 2-V_{S}^{2}}{V_{P}^{2}-V_{S}^{2}},
$$

and combining Eqs. (5) and (7) gives:

$$
\frac{V_{P}}{V_{R}}=\sqrt{\frac{2(1-\vartheta)}{(1-2 \vartheta)} \cdot \frac{(1+\vartheta)^{2}}{(0.87+1.12 \vartheta)^{2}}} .
$$

Also, the dynamic elastic modulus can be extracted from Eq. (6) as below:

$$
E_{d}=2 \rho V_{S}^{2}(1+\vartheta) \text {. }
$$

Then, according to Eq. (10) for calculation of $E_{d}$, the values of $\rho, \vartheta$, and $V_{S}$ are needed. The density value $(\rho)$ for normal concrete is about $2400 \mathrm{~kg} / \mathrm{m}^{3}$, and the Poisson's ratio $(\vartheta)$ lies generally in the range of 0.15 to 0.22 and can be calculated by Eqs. (8) or (9) based on $V_{P}$ and $V_{S}$ or $V_{P}$ and $V_{R}$, respectively. Therefore, to evaluate $E_{d}$ by NDT techniques, measuring the values of $V_{P}$ and $V_{S}$ or measuring the values of $V_{P}$ and $V_{R}$ is required.

In this investigation, the UPV test and MIRA $3 \mathrm{D}$ provided the average $\mathrm{P}$-wave and $\mathrm{S}$-wave velocities, respectively, for each pier. So, using the $\mathrm{P}$-wave and S-wave velocities, Poisson's ratio and the dynamic modulus of elasticity are computed from Eqs. (8) and (10). The results for dynamic modulus of elasticity of the bridge piers are shown in Table 2.

\subsection{Calculation of the static elastic modulus}

NDT methods usually estimate the in-place dynamic elastic modulus of concrete. Thus, it is important to establish an appropriate relation between the dynamic modulus of elasticity $\left(E_{d}\right)$ obtained from NDT results and the static modulus of elasticity $\left(E_{C}\right)$.

Various empirical relations have been developed for calculation of the static modulus by dynamic modulus of elasticity of concrete the simplest of which, proposed by Lydon and Balendran [16], is shown in Eq. (11):

$$
E_{C}=0.83 E_{d}
$$

The British Code of concrete structures (CP110, 1972) [25] gives Eq. (12) between the static and dynamic moduli of elasticity:

$$
E_{C}=1.25 E_{d}-19,
$$

in which both moduli are expressed in GPa. 
Table 2. Computation of the dynamic modulus of elasticity.

\begin{tabular}{cccccc}
\hline Piers no. & $\boldsymbol{V}_{\boldsymbol{P}}(\mathbf{m} / \mathbf{s})$ & $\boldsymbol{V}_{\boldsymbol{S}}(\mathbf{m} / \mathbf{s})$ & $\boldsymbol{\vartheta}$ & $\boldsymbol{\rho}\left(\mathbf{T} / \mathbf{m}^{\mathbf{3}}\right)$ & $\boldsymbol{E}_{\boldsymbol{d}}(\mathbf{G P a})$ \\
\hline $\mathbf{1}$ & 4,163 & 2,449 & 0.23539 & 2.4 & 35.57 \\
$\mathbf{2}$ & 4,354 & 2,561 & 0.23551 & 2.4 & 38.90 \\
$\mathbf{3}$ & 4,070 & 2,394 & 0.23549 & 2.4 & 33.99 \\
$\mathbf{4}$ & 4,276 & 2,515 & 0.23554 & 2.4 & 37.51 \\
$\mathbf{5}$ & 4,140 & 2,435 & 0.23555 & 2.4 & 35.16 \\
$\mathbf{6}$ & 4,221 & 2,483 & 0.23543 & 2.4 & 36.56 \\
$\mathbf{7}$ & 4,075 & 2,397 & 0.23547 & 2.4 & 34.07 \\
$\mathbf{8}$ & 4,247 & 2,498 & 0.23553 & 2.4 & 37.01 \\
$\mathbf{9}$ & 4,231 & 2,489 & 0.23539 & 2.4 & 36.74 \\
$\mathbf{1 0}$ & 4,083 & 2,402 & 0.23537 & 2.4 & 34.21 \\
$\mathbf{1 1}$ & 4,240 & 2,494 & 0.23549 & 2.4 & 36.89 \\
$\mathbf{1 2}$ & 4,316 & 2,539 & 0.23539 & 2.4 & 38.23 \\
$\mathbf{1 3}$ & 4,199 & 2,470 & 0.23545 & 2.4 & 36.18 \\
$\mathbf{1 4}$ & 4,206 & 2,474 & 0.23549 & 2.4 & 36.30 \\
$\mathbf{1 5}$ & 4,155 & 2,444 & 0.23549 & 2.4 & 35.42 \\
$\mathbf{1 6}$ & 4,116 & 2,421 & 0.23551 & 2.4 & 34.76 \\
$\mathbf{1 7}$ & 4,175 & 2,456 & 0.23541 & 2.4 & 35.77 \\
$\mathbf{1 8}$ & 4,085 & 2,403 & 0.23543 & 2.4 & 34.24 \\
\hline & & & & &
\end{tabular}

Also, Eq. (13) was suggested for both lightweight and normal concretes:

$$
E_{C}=1.04 E_{d}-4.1 \text {. }
$$

Furthermore, for both lightweight and normal concretes, a general relationship between the static and dynamic moduli of elasticity was developed by Popovics et al. [20], as shown in Eq. (14). In this equation, $k=0.23$ for units of $E_{d}$ in psi and density $\rho$ in $\mathrm{Lb} / \mathrm{ft}^{3}$; and $k=427.711$ for $E_{d}$ in GPa and $\rho$ in $\mathrm{kg} / \mathrm{m}^{3}$ :

$$
E_{C}=k E_{d}^{1.4} \rho^{-1} .
$$

The relationships proposed above are all based on experimental results obtained from testing different concrete specimens. These relationships give different results for prediction of static modulus of elasticity. It is not clear which proposed relationship better matches the concrete of the bridge piers. In this research, therefore, the mean value of the relationships is considered as the final value. Table 3 shows the calculated values for static modulus of elasticity of the bridge piers. The last column of this table gives the average of the relationships and is considered as a decisive result.

\subsection{Calculation of the compressive strength based on elastic modulus}

The expression for calculating the static modulus (secant modulus) of elasticity of normal weight concrete,
$E_{C}(\mathrm{GPa})$, based on compressive strength of standard test cylinders, $f_{c}^{\prime}(\mathrm{MPa})$, recommended by ACI 31802, [26] for structural calculations, is shown in Eq. (15):

$$
E_{C}=4.73\left(f_{c}^{\prime}\right)^{0.5}
$$

when the density of concrete $\rho\left(\mathrm{kg} / \mathrm{m}^{3}\right)$ is specified, the expression for calculation of the static modulus will be as in Eq. (16):

$$
E_{c}=43 \rho^{1.5}\left(f_{c}^{\prime}\right)^{0.5} \times 10^{-6} .
$$

Hansen [17] proposed the relationship between the dynamic modulus of elasticity and the compressive strength of cube specimens as in Eq. (17):

$$
E_{d}=5.31\left(f_{c}^{\prime}\right)^{0.5}+5.83,
$$

where $E_{d}$ is in GPa and $f_{c}^{\prime}$ is in MPa.

To convert the compressive strength of the cube specimens to compressive strength of the cylinder specimens, the coefficient of 0.833 is used.

Table 4 gives the obtained values for compressive strength of bridge piers (according to standard cylinder specimens) based on static or dynamic modulus of elasticity. The average of the obtained values from Eqs. (15) and (17) is considered as the final result.

\section{Discussion}

Compressive strengths of the concrete bridge piers based only on $\mathrm{P}$-wave velocity data are calculated in 
Table 3. Computation of the static modulus of elasticity.

\begin{tabular}{|c|c|c|c|c|c|}
\hline $\begin{array}{c}\text { Piers } \\
\text { no. }\end{array}$ & $E_{d}(\mathrm{GPa})$ & $\begin{array}{c}E_{C}(\mathrm{GPa}) \\
\text { Eq. }(12)\end{array}$ & $\begin{array}{c}E_{C}(\mathrm{GPa}) \\
\text { Eq. }(13)\end{array}$ & $\begin{array}{c}E_{C}(\mathrm{GPa}) \\
\text { Eq. }(14)\end{array}$ & $\begin{array}{c}E_{C}(\mathrm{GPa}) \\
\text { Mean value }\end{array}$ \\
\hline 1 & 35.57 & 25.46 & 32.89 & 26.42 & 28.26 \\
\hline 2 & 38.90 & 29.63 & 36.36 & 29.95 & 31.98 \\
\hline 3 & 33.99 & 23.49 & 31.25 & 24.80 & 26.51 \\
\hline 4 & 37.51 & 27.89 & 34.91 & 28.47 & 30.42 \\
\hline 5 & 35.16 & 24.95 & 32.47 & 26.01 & 27.81 \\
\hline 6 & 36.56 & 26.70 & 33.92 & 27.46 & 29.36 \\
\hline 7 & 34.07 & 23.59 & 31.33 & 24.88 & 26.60 \\
\hline 8 & 37.01 & 27.26 & 34.39 & 27.93 & 29.86 \\
\hline 9 & 36.74 & 26.93 & 34.11 & 27.65 & 29.56 \\
\hline 10 & 34.21 & 23.76 & 31.48 & 25.03 & 26.76 \\
\hline 11 & 36.89 & 27.11 & 34.27 & 27.81 & 29.73 \\
\hline 12 & 38.23 & 28.79 & 35.66 & 29.23 & 31.23 \\
\hline 13 & 36.18 & 26.23 & 33.53 & 27.06 & 28.94 \\
\hline 14 & 36.30 & 26.38 & 33.65 & 27.19 & 29.07 \\
\hline 15 & 35.42 & 25.28 & 32.74 & 26.28 & 28.10 \\
\hline 16 & 34.76 & 24.45 & 32.05 & 25.59 & 27.36 \\
\hline 17 & 35.77 & 25.71 & 33.10 & 26.64 & 28.48 \\
\hline 18 & 34.24 & 23.80 & 31.51 & 25.06 & 26.79 \\
\hline
\end{tabular}

Table 4. Computation of the concrete strength based on elastic modulus of elasticity.

\begin{tabular}{cccccc}
\hline $\begin{array}{c}\text { Piers } \\
\text { no. }\end{array}$ & $\begin{array}{c}\boldsymbol{E}_{\boldsymbol{d}} \\
(\mathbf{G P a})\end{array}$ & $\begin{array}{c}\boldsymbol{E}_{\boldsymbol{C}}(\mathbf{G P a}) \\
\text { Mean value }\end{array}$ & $\begin{array}{c}\boldsymbol{f}_{\boldsymbol{c}}^{\prime}(\mathbf{M P a}) \\
\mathbf{E q .}(\mathbf{1 5})\end{array}$ & $\begin{array}{c}\boldsymbol{f}_{\boldsymbol{c}}^{\prime}(\mathbf{M P a}) \\
\mathbf{E q .}(\mathbf{1 7})\end{array}$ & $\begin{array}{c}\boldsymbol{f}_{c}^{\prime}(\mathbf{M P a}) \\
\text { Mean value }\end{array}$ \\
\hline $\mathbf{1}$ & 35.57 & 25.62 & 29.34 & 26.13 & 27.74 \\
$\mathbf{2}$ & 38.90 & 29.09 & 37.83 & 32.31 & 35.07 \\
$\mathbf{3}$ & 33.99 & 24.00 & 25.75 & 23.43 & 24.59 \\
$\mathbf{4}$ & 37.51 & 27.63 & 34.12 & 29.65 & 31.89 \\
$\mathbf{5}$ & 35.16 & 25.20 & 28.39 & 25.41 & 26.90 \\
$\mathbf{6}$ & 36.56 & 26.65 & 31.75 & 27.90 & 29.82 \\
$\mathbf{7}$ & 34.07 & 24.09 & 25.94 & 23.56 & 24.75 \\
$\mathbf{8}$ & 37.01 & 27.11 & 32.85 & 28.72 & 30.79 \\
$\mathbf{9}$ & 36.74 & 26.83 & 32.18 & 28.23 & 30.20 \\
$\mathbf{1 0}$ & 34.21 & 24.23 & 26.24 & 23.79 & 25.02 \\
$\mathbf{1 1}$ & 36.89 & 26.99 & 32.56 & 28.50 & 30.53 \\
$\mathbf{1 2}$ & 38.23 & 28.38 & 36.00 & 31.01 & 33.51 \\
$\mathbf{1 3}$ & 36.18 & 26.25 & 30.80 & 27.21 & 29.01 \\
$\mathbf{1 4}$ & 36.30 & 26.38 & 31.11 & 27.43 & 29.27 \\
$\mathbf{1 5}$ & 35.42 & 25.47 & 29.00 & 25.87 & 27.43 \\
$\mathbf{1 6}$ & 34.76 & 24.79 & 27.47 & 24.73 & 26.10 \\
$\mathbf{1 7}$ & 35.77 & 25.83 & 29.82 & 26.48 & 28.15 \\
$\mathbf{1 8}$ & 34.24 & 24.26 & 26.31 & 23.85 & 25.08 \\
\hline
\end{tabular}


Table 5. Comparison of the concrete strength based on $V_{p}$ and $\left(V_{p} \& V_{s}\right)$.

\begin{tabular}{ccccc}
\hline $\begin{array}{c}\text { Piers } \\
\text { no. }\end{array}$ & $\begin{array}{c}\boldsymbol{f}_{\boldsymbol{c}}^{\prime}(\mathbf{M P a}) \\
\text { based on } \mathbf{~ V ~}\end{array}$ & $\begin{array}{c}\boldsymbol{f}_{\boldsymbol{c}}^{\prime}(\mathbf{M P a}) \\
\text { based on } \mathbf{~} \mathbf{p} \text { \& Vs }\end{array}$ & $\begin{array}{c}\text { Percentage of } \\
\text { difference }\end{array}$ & $\begin{array}{c}\boldsymbol{f}_{\boldsymbol{c}}^{\prime}(\mathrm{MPa}) \\
\text { Mean value }\end{array}$ \\
\hline $\mathbf{1}$ & 29.85 & 27.74 & 7.07 & 28.80 \\
$\mathbf{2}$ & 35.26 & 35.07 & 0.54 & 35.17 \\
$\mathbf{3}$ & 27.52 & 24.59 & 10.65 & 26.06 \\
$\mathbf{4}$ & 32.94 & 31.89 & 3.19 & 32.42 \\
$\mathbf{5}$ & 29.25 & 26.90 & 8.03 & 28.08 \\
$\mathbf{6}$ & 31.40 & 29.82 & 5.03 & 30.61 \\
$\mathbf{7}$ & 27.64 & 24.75 & 10.46 & 26.20 \\
$\mathbf{8}$ & 32.12 & 30.79 & 4.14 & 31.46 \\
$\mathbf{9}$ & 31.67 & 30.20 & 4.64 & 30.94 \\
$\mathbf{1 0}$ & 27.84 & 25.02 & 10.13 & 26.43 \\
$\mathbf{1 1}$ & 31.92 & 30.53 & 4.35 & 31.23 \\
$\mathbf{1 2}$ & 34.11 & 33.51 & 1.76 & 33.81 \\
$\mathbf{1 3}$ & 30.80 & 29.01 & 5.81 & 29.91 \\
$\mathbf{1 4}$ & 30.99 & 29.27 & 5.55 & 30.13 \\
$\mathbf{1 5}$ & 29.64 & 27.43 & 7.46 & 28.54 \\
$\mathbf{1 6}$ & 28.65 & 26.10 & 8.90 & 27.38 \\
$\mathbf{1 7}$ & 30.16 & 28.15 & 6.66 & 29.16 \\
$\mathbf{1 8}$ & 27.88 & 25.08 & 10.04 & 26.48 \\
\hline & & & & \\
\end{tabular}

Section 4 of this paper, and the final results are shown in the second column of Table 5 . Also, based on both $\mathrm{P}$-wave and S-wave velocity data, strengths of the concrete piers are determined in Section 5.3 and presented in the third column of Table 5. The fourth column of this table shows the percentage of difference between these two strengths. The maximum difference between the two methods is about 10 percent. Thus, two quite different NDT techniques generate very close results for strength of the concrete piers, indicating the accuracy of the methods. The average of the two methods is presented in the last column of Table 5 and used as the final results for the compressive strength estimate of the concrete piers. These final strengths are obtained from averaging and combination of several empirical models and using two NDT techniques. The obtained results are more accurate than the condition in which one empirical model and one NDT technique were used.

In addition to compressive strength of the concrete, the static modulus of elasticity $\left(E_{C}\right)$ can be used as an indicator of the condition of the in-place concrete. The comparison between the initial or prescribed $E_{C}$ during construction $\left(E_{C}\right)_{P}$ and the in-place (existing) $E_{C}$ provides a basis for how the concrete has deteriorated during the time.

The in-place (existing) strength and static moduli of elasticity of the piers are shown in the second and third columns of Table 6 . According to the constructional detailing of the bridge, the initial or prescribed compressive strength of the concrete was $\left(f_{c}^{\prime}\right)_{p}=35 \mathrm{MPa}$, and the initial or prescribed elasticity of the piers at the time of construction was estimated as $\left(E_{C}\right)_{p}=28 \mathrm{GPa}$. The ratio of the existing strength and also modulus of elasticity with respect to the prescribed values at the time of construction are presented in Table 6. Generally, according to section 5.6.5.4 of ACI $318-08$ [27], a ratio of 0.85 or greater is in the acceptable range. For more accuracy, the mean value of the ratios is considered to assess the piers condition. The last column of Table 6 shows the condition and state of the health of the piers.

The results show that for a large number of piers, the ratios are acceptable and the piers are in the good condition. However, in case the ratios are not acceptable for the piers, they indicate some loss of strength having occurred; therefore, such piers should be considered for rehabilitation.

\section{Conclusion}

In this investigation, by measuring both $\mathrm{P}$ - and $\mathrm{S}$-wave velocities, the strength and elastic moduli of piers of a concrete bridge are estimated. Two different methods were used to calculate the strength of the concrete. The first method was based only on $\mathrm{P}$-wave velocity data and the second on both $\mathrm{P}$ - and S-wave velocity data along with calculation of elastic modulus. The results of the two different techniques are very close, which indicates the accuracy of the methods. A summary of the results of this research is as follows: 
Table 6. Control of the bridge piers condition.

\begin{tabular}{ccccccc}
\hline Piers no. & $\begin{array}{c}\boldsymbol{f}_{c}^{\prime} \\
(\mathbf{M P a})\end{array}$ & $\begin{array}{c}\boldsymbol{E}_{\boldsymbol{C}} \\
(\mathbf{G P a})\end{array}$ & $\boldsymbol{f}_{c}^{\prime} /\left(\boldsymbol{f}_{\boldsymbol{c}}^{\prime}\right)_{p}$ & $\boldsymbol{E}_{\boldsymbol{C}} /\left(\boldsymbol{E}_{\boldsymbol{C}}\right)_{p}$ & $\begin{array}{c}\text { Mean } \\
\text { ratio }\end{array}$ & $\begin{array}{c}\text { Pier } \\
\text { condition }\end{array}$ \\
\hline $\mathbf{1}$ & 28.80 & 25.62 & 0.82 & 0.92 & 0.87 & Good \\
$\mathbf{2}$ & 35.17 & 29.09 & 1.00 & 1.04 & 1.02 & Good \\
$\mathbf{3}$ & 26.06 & 24.00 & 0.74 & 0.86 & 0.80 & Poor \\
$\mathbf{4}$ & 32.42 & 27.63 & 0.93 & 0.99 & 0.96 & Good \\
$\mathbf{5}$ & 28.08 & 25.20 & 0.80 & 0.90 & 0.85 & Good \\
$\mathbf{6}$ & 30.61 & 26.65 & 0.87 & 0.95 & 0.91 & Good \\
$\mathbf{7}$ & 26.20 & 24.09 & 0.75 & 0.86 & 0.80 & Poor \\
$\mathbf{8}$ & 31.46 & 27.11 & 0.90 & 0.97 & 0.93 & Good \\
$\mathbf{9}$ & 30.94 & 26.83 & 0.88 & 0.96 & 0.92 & Good \\
$\mathbf{1 0}$ & 26.43 & 24.23 & 0.76 & 0.87 & 0.81 & Poor \\
$\mathbf{1 1}$ & 31.23 & 26.99 & 0.89 & 0.96 & 0.93 & Good \\
$\mathbf{1 2}$ & 33.81 & 28.38 & 0.97 & 1.01 & 0.99 & Good \\
$\mathbf{1 3}$ & 29.91 & 26.25 & 0.85 & 0.94 & 0.90 & Good \\
$\mathbf{1 4}$ & 30.13 & 26.38 & 0.86 & 0.94 & 0.90 & Good \\
$\mathbf{1 5}$ & 28.54 & 25.47 & 0.82 & 0.91 & 0.86 & Good \\
$\mathbf{1 6}$ & 27.38 & 24.79 & 0.78 & 0.89 & 0.83 & Poor \\
$\mathbf{1 7}$ & 29.16 & 25.83 & 0.83 & 0.92 & 0.88 & Good \\
$\mathbf{1 8}$ & 26.48 & 24.26 & 0.76 & 0.87 & 0.81 & Poor \\
\hline & & & & & &
\end{tabular}

- For the existing concrete with an unknown mix design, using only one empirical model to estimate the strength and elastic moduli of concrete can lead to unrealistic results, and using the average value of several appropriate empirical models is more accurate;

- Using only one NDT method for evaluation of the characteristics of the desired concrete faces some errors, and using the combination of two or more nondestructive methods is more precise;

- The evaluation of the static modulus of elasticity can be used as an additional indicator to assess the condition of the in-place concrete;

- The combination of two criteria of strength and elasticity gives a more accurate scale for assessment of the concrete condition;

- The results show the ability and efficiency of the combination of two different NDT methods (P-wave and $\mathrm{S}$-wave measurements) to estimate the strength and health conditions of the concrete structure.

\section{Nomenclature}

$\begin{array}{ll}A & \text { Constant coefficient of curve fitting } \\ B & \text { Constant coefficient of curve fitting } \\ E_{C} & \text { Static modulus of elasticity }(\mathrm{GPa}) \\ \left(E_{C}\right)_{p} & \begin{array}{l}\text { Prescribed static modulus of elasticity } \\ (\mathrm{GPa})\end{array}\end{array}$

$E_{d} \quad$ Dynamic modulus of elasticity (GPa)

$F_{C} \quad$ Compressive strength of concrete (MPa)

$f_{c}^{\prime} \quad$ Compressive strength of concrete (MPa)

$\left(f_{c}^{\prime}\right)_{p} \quad$ Prescribed compressive strength of concrete $(\mathrm{MPa})$

$R \quad$ Correlation coefficient

$R^{2} \quad$ R-squared or coefficient of determination

$V_{P} \quad$ P-wave velocity $(\mathrm{km} / \mathrm{sec}$ or $\mathrm{m} / \mathrm{sec})$

$V_{R} \quad$ R-wave velocity $(\mathrm{km} / \mathrm{sec}$ or $\mathrm{m} / \mathrm{sec})$

$V_{S} \quad$ S-wave velocity $(\mathrm{km} / \mathrm{sec}$ or $\mathrm{m} / \mathrm{sec})$

$\rho \quad$ Density of concrete $\left(\mathrm{kg} / \mathrm{m}^{3}\right)$

$\vartheta \quad$ Poisson's ratio

\section{References}

1. Jones, R., Non-Destructive Testing of Concrete, Cambridge University Press, London (1962).

2. Bungey, J.H. and Millard, S.G., Testing of Concrete in Structures, Third Ed., Blackie Academic \& Professional, an imprint of Chapman \& Hall (1996).

3. Turgut, P. "Evaluation of the ultrasonic pulse velocity data coming on the field", Fourth International Conference on NDE in Relation to Structural Integrity for Nuclear and Pressurised Components, London (2004). 
4. Trtnik, G., Kavaciiĉ, F. and Turk, G. "Prediction of concrete strength using ultrasonic pulse velocity and artificial neural networks", Ultrasonic, Elsevier, 49(1), pp. 53-60 (2009).

5. Neville, A.M., Properties of Concrete, 5th Ed., Pearson Education Limited, Edinburgh Gate, Harlow, Essex CM20 2JE, England (2011).

6. Yehia, S., Abudayyeh, O., Nabulsi, S. and Abdelqader, I. "Detection of common defects in concrete bridge decks using nondestructive evaluation techniques", $J$. Bridge Eng., 12(2), pp. 215-226 (2007).

7. Dawood, N., Marzouk, H., Hussein, H. and Gillis, N. "Nondestructive assessment of a Jetty bridge structure using impact-echo and shear-wave techniques", $J$. Bridge Eng., ASCE, 18(8), pp. 801-809 (2013).

8. Zein, A.S. and Gassman, S.L. "Frequency spectrum analysis of impact-echo waveforms for t-beams", $J$. Bridge Eng., 15(6), pp. 705-714 (2010).

9. Carcano, R.S. and Moreno, E.I. "Evaluation of concrete made with crushed limestone aggregate based on ultrasonic pulse velocity", Construction and Building Materials, 22, pp. 1225-1231 (2008).

10. Kewalramani, M.A. and Gupta, R. "Concrete compressive strength prediction using pulse velocity through artificial neural networks", Automation in Construction, Elsevier, 15 (2006).

11. Bilgehan, M. and Turgut, P. "Artificial neural network approach to predict compressive strength of concrete through ultrasonic pulse velocity", Research in Nondestructive Evaluation, 21, pp. 1-17 (2010).

12. Haza, A.O.D.L., Samokrutov, A.A. and Samokrutov, P.A. "Assessment of concrete structures using the MIRA and Eyecon ultrasonic shear wave devices and the SAFT-C image reconstruction technique", Construction and Building Materials, 38, pp. 1276-1291 (2013).

13. Malcolm, K.L. and Honggang, C. "Combining multiple NDT methods to improve testing effectiveness", Construction and Building Materials, 38, pp. 1310-1315 (2013).

14. Bishko, A.V., Samokrutov, A.A. and Shevaldykin, V.G. "Ultrasonic Echo-Pulse tomography of concrete using shear waves low-frequency phased antenna arrays", 17th World Conference on Nondestructive Testing, 25-28 Oct, Shanghai, China (2008).

15. Birgul, R. "Hilbert transformation of waveforms to determine shear wave velocity in concrete", Journal of Cement and Concrete Research, pp. 696-700 (2009).

16. Lydon, F.D. and Balendran, R.V. "Some observations on elastic properties of plain concrete", Journal of Cement and Concrete Research, 16(3), pp. 314-24 (1986).

17. Hansen, T.C. "Recycled aggregate and recycled aggregate concrete", Material and Structures (RILEM), 19(111), May-June, pp. 201-204 (1986).
18. Gonen, T. "Mechanical and fresh properties of fiber reinforced self-compacting lightweight concrete", Scientia Iranica, A, 22(2), pp. 313-318 (2015).

19. Salman, M.M. and Al-Amawee, A.H. "The ratio between static and dynamic modulus of elasticity in normal and high strength concrete", Journal of Engineering and Development, 10(2), pp. 163-174 (2006).

20. Popovics, J.S., Zemajtis, J. and Shkolnik, I. "A study of static and dynamic modulus of elasticity of concrete", ACI Materials Journal, pp. 1-8 (2008).

21. Less, T. and Adeli, H. "Computational earthquake engineering of bridges", Scientia Iranica, Transaction A: Civil Engineering, 17(5), pp. 325-338 (2010).

22. Vasseghi, A., Bahrani, M.K. and Soltani, M. "Seismic retrofit of a typical reinforced concrete bridge bent in Iran", Scientia Iranica A, 22(4), pp. 1402-1410 (2015).

23. Germann Instruments "MIRA 3D shear wave tomographer manual" Report, Germann Instruments (2014).

24. Qixian, L. and Bungeyt, J.H. "Using compression wave ultrasonic transducers to measure the velocity of surface waves and hence determine dynamic modulus of elasticity for concrete", Construction and Building Materials, 10(4), pp. 237-242 (1996).

25. CP 110, Code of Practice for the Structural Use of Concrete, British Standards Institution, London (1972).

26. ACI 318-02, Building Code Requirements for Structural Concrete, American Concrete Institute, Farmington Mills, Michigan (2002).

27. ACI 318-08, Building Code Requirements for Structural Concrete and Commentary, American Concrete Institute, Section 5.6.5.4 (2007).

\section{Biographies}

Mohammad Ali Hadianfard was born in Shiraz, Iran in 1969. He obtained his BS degree in Civil Engineering from Shiraz University, Iran in 1992. He continued his studies on Structures in Shiraz University and received his MS and PhD degrees in 1995 and 2002, respectively. $\mathrm{He}$ is currently an Associate Professor of Civil Engineering. He has published about 20 journal papers. Also, he has presented about 25 papers in the international and 65 papers in the national conferences. Moreover, he has contributed in writing 7 national standards of Iran. His research interests are rehabilitation, blast loading, progressive collapse, steel connections and semi-rigid connections, nonlinear analysis, and structural reliability.

Hesham Marzouk, FACI, is a Professor of the Civil Engineering Department at Ryerson University, Toronto, Canada. He received his MSc and $\mathrm{PhD}$ degrees from the University of Saskatchewan, Saskatoon, Canada. He is a member of ACI Committees 209, Creep and Shrinkage in Concrete, and 213, Lightweight 
Aggregate and Concrete. He is a voting member of the Canadian Standard Association Committee for the Offshore Structures S474. His research interests include structural and material properties of highstrength and ultra-high performance fiber reinforced concrete, offshore design, creep, finite element analysis, and Structural Health Monitoring (SHM).
Canon Shafieyan is Laboratory Teaching Assistant - Geotechnical Properties of Soils at Ryerson University, Toronto, Canada. He also is member of Cole Engineering Group Ltd. He earned M Eng (Master of Engineering) of Civil Engineering from the Ryerson University, Toronto, Canada in 2014. His research interest is structural health monitoring of bridges. 